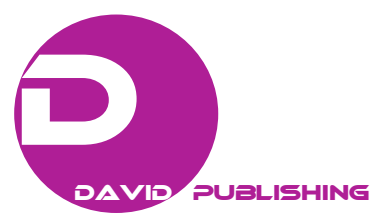

\title{
Components Qualification for the Safe Operation of Nuclear Power Plants
}

Holger Schmidt ${ }^{1}$, Martin Beetz ${ }^{1}$, Ingo Ganzmann ${ }^{1}$, Achim Beisiegel ${ }^{2}$, Thomas Wagner ${ }^{2}$, Christian Bonneau ${ }^{3}$, Darryl Gordon ${ }^{4}$ and Sun Jing 5

1. AREVA GmbH-Thermal Hydraulics and Components Testing, Paul-Gossenstr 100, Erlangen 91052, Germany

2. AREVA GmbH-Thermal Hydraulics and Components Testing Seligenstädter Strasse 100, Karlstein 63791, Germany

3. AREVA SAS-Thermal Hydraulics and Components Testing 30 boulevard de l'Industrie, Le Creusot 71205, France

4. AREVA Inc.-Thermal Hydraulics and Components Testing 3315 Old Forest Road, Lynchburg VA 24501, USA

5. Keysur International F11, Tower A, Millennium Plaza, No.72, Beijing 100037, China

Received: May 05, 2016 / Accepted: July 05, 2016 / Published: October 31, 2016.

\begin{abstract}
AREVA operates a world-wide unique thermal hydraulic platform to ensure high safety standards in the nuclear industries. This platform is operated as an accredited test and inspection body according to ISO 17025 and 17020 to grant a high and independently confirmed quality standard. The accreditation also ensures the independency of the organization and confidentiality to the individual stakeholders, for example research centers, utilities, components suppliers, engineering companies and vendors. Especially for nuclear power plants, it is very relevant to consider that reliability depends on the integrity of its components during its life time- from design through construction, operation and maintenance. For example, a typical NPP (nuclear power plant) has 1,000 to 2,000 large valves and 7,500 to 12,500 small valves, of which about 200 to 400 are designated Safety Class 1 . The qualification of these Safety Class 1 components is relevant for reactor new builds but also for installed plants. This paper explains newly established qualification tasks, the corresponding testing infrastructure, and the state of the art of testing technology. By way of example, the paper describes the program and possible sequence of qualifying NPP safety-related components.
\end{abstract}

Key words: Components testing, nuclear qualification, thermal hydraulics testing, nuclear safety.

\section{Introduction}

Ensuring that safety and regulatory standards are met in new nuclear plant projects or large modification projects at existing nuclear plants requires the qualification of any new or modified components. The use of qualified components to ensure safety functions is valid for instrumentation and control components as well as for all safety-related mechanical components, which include in-core components like control rods and all relevant components outside the core, such as pumps and valves. The general philosophy is for all of these components to undergo a rigorous qualification

Corresponding author: Dr. Holger Schmidt, worldwide technology line manager, research fields: thermal hydraulics and components testing. process; even though the codes and standards (e.g. Refs. [1-3]) they must meet differ from component to component or plant to plant. Additionally, a previously qualified component that is being used in a new application must undergo a qualification process to ensure that it will have the desired performance in the new application. This need has become evident as the industry's level of safety knowledge has increased over the years and the push for power up rates, extended lifetimes, and new plant designs has led to new requirements and new applications for plant equipment. If it is not possible to confirm the required functioning of a component based on engineering work and previously performed qualification tests, it becomes necessary to perform new qualification programs, including the appropriate qualification tests. Because 
the requirements are so stringent, sub-suppliers often have difficulty in performing the qualification testing in-house. To address this critical supply-chain issue, AREVA decided to open its testing and qualification facility to all stakeholders in the nuclear industry, including utilities, authorities, research centers, component manufacturers or engineering companies. To meet the high safety and qualification standards required by these stakeholders, AREVA's testing and qualification facility has been accredited to the ISO 17025 and ISO 17020 standards [4]. This accreditation also ensures the independence of the facility and confidentiality of the individual stakeholders. Because the various stakeholders have different qualification requirements, a flexible infrastructure and accreditation have been established. This means that, as long as the tests and qualifications are based on the basic infrastructure and the measurement signals are in the accredited range (see Table 1), the accreditation is valid. Although accreditation is always the responsibility of the local governmental-linked organization, acceptance by the ILAC (International Laboratory Accreditation Cooperation) ensures that laboratory quality meets worldwide standards.

Using safety-related valves as an example, this paper examines a typical qualification process required to ensure the proper functioning of equipment in a new or modified nuclear power plant.

\section{Qualification Concept Using the Example of Safety-Related Valves}

The purpose of the qualification is to demonstrate that the component fulfills its design function until the end of its scheduled operational time and in the event of accident conditions. Therefore, it is necessary to analyze the entire life cycle of the component and the related parts of the components that can fail. From this analysis, specific tests will be determined. In a typical NPP (nuclear power plant), about 200 to 400 valves are safety related with very different requirements. A sample structure for a test program to qualify safety-related valves is presented below.

\subsection{Containment Environmental Effects and Aging}

In the case of electrically operated valves, the functioning of the actuators has to be demonstrated. To consider the entire lifecycle, a set of tests is commonly performed (Fig. 1) [5]. These tests can be split into aging tests, accident-condition tests, and post-accident tests. The aging test simulates component operation until the end of life. This test can include thermal, operational, pressurization, radiation, and vibration aging. These aging processes have to be reduced in time scale. Therefore, higher temperature rates and respectively higher dose rates are applied, which will have a similar effect as full-time operation at lower levels. In addition, open/close cycles and containment pressure tests are performed, using applied torque and vibration aging.

Following the aging part of the qualification program, accident conditions are applied. Typically, it is assumed that an earthquake has occurred, which may cause the accident directly or indirectly. Therefore, related vibration tests are performed, followed by a LOCA (loss of coolant accident) test, which represents the containment atmosphere following a break in the primary coolant system boundary. This typically

Table 1 Accredited measuring range.

\begin{tabular}{ll}
\hline Measurement & Measuring range \\
\hline Temperature & $0{ }^{\circ} \mathrm{C}$ to $1,100{ }^{\circ} \mathrm{C}$ \\
Pressure & $10 \mathrm{~Pa}$ to $40 \mathrm{MPa}$ \\
Volume flow & $0.1 \mathrm{~L} / \mathrm{h}$ to $100,000 \mathrm{~m}^{3} / \mathrm{h}$ \\
Mass flow & $0.005 \mathrm{~kg} / \mathrm{h}$ to $4,000 \mathrm{~kg} / \mathrm{s}$ \\
Force & $1 \mathrm{~N}$ to $10,000 \mathrm{kN}$ \\
Torque & $1 \mathrm{Nm}$ to $50,000 \mathrm{Nm}$ \\
Length & $1 \mu \mathrm{m}$ to $10 \mathrm{~m}$ \\
Velocity & $1 \mathrm{~mm} / \mathrm{s}$ to $100 \mathrm{~m} / \mathrm{s}$ \\
Acceleration & 0.5 to $1,000 \mathrm{~g}$ \\
Current & $1 \mu \mathrm{A}$ to $85,000 \mathrm{~A}$ \\
Voltage & $1 \mathrm{mV}$ to $4 \mathrm{kV}$ \\
Electrical power & up to $20 \mathrm{MW}$ \\
Effective power & up to $420 \mathrm{~kW}$ \\
Mass & $0.005 \mathrm{~g}$ to $3,000 \mathrm{~kg}$ \\
Insulation resistance & $50 \mathrm{k} \Omega$ to $200 \mathrm{~T} \Omega$ \\
\hline
\end{tabular}




\section{Preconditioning (aging tests)}

1. Thermal Aging

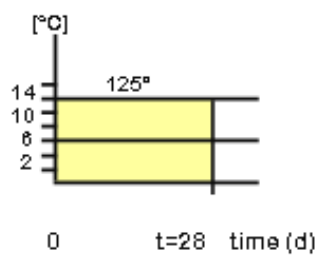

4. RadiologicalAging

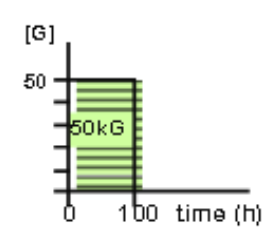

2 Torque

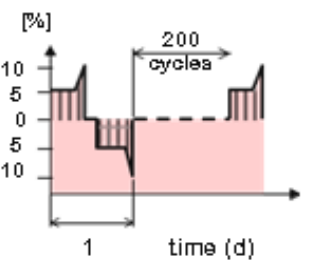

5. Vhration Aging

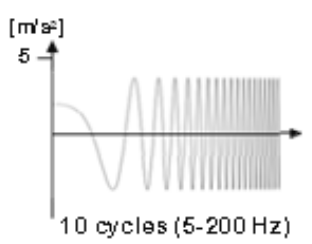

3. Pressurization

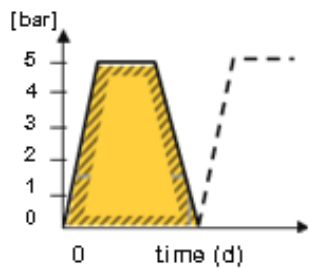

6. Functional Testing

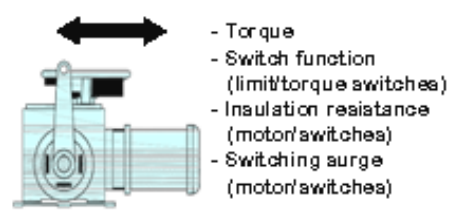

Simulation of accident tests

1. Vibration Test

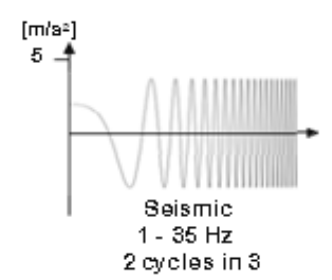

3. Accident Radiation

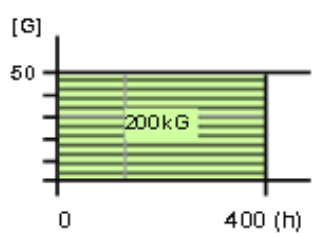

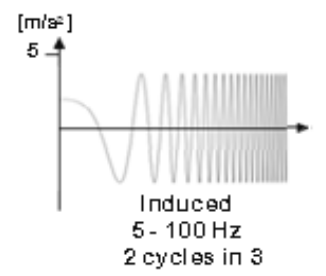

4. Postaccident Conditions

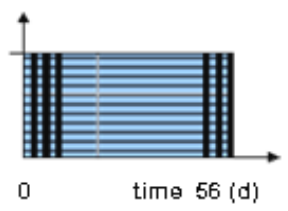

2. LOCA Test

$\left[{ }^{\circ} \mathrm{C}\right]$

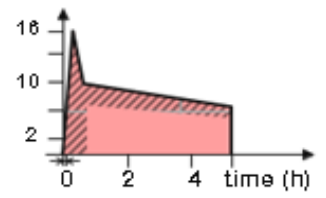

5. Wechanical Service Life

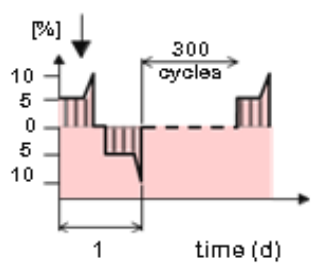

Fig. 1 Steps of an actuator qualification.

involves sharp increases in pressure and temperature under high humidity and related water chemistry. For this purpose, testing setups are necessary to control the appropriate ambient conditions. To avoid the installation of a radiation source in the containment atmosphere test vessel, the actuator is typically placed in a second test step in front of a radiation source to represent the assumed increased radiation during an accident. Depending on the requirements of the valve, it is often the case that the valve has to be activated in the post-LOCA phase. Therefore, it is a typical requirement that the actuator has to withstand a post-LOCA atmosphere, which can be realized in a test vessel similar to that used in the LOCA atmosphere tests, but at lower pressure and temperature levels. Finally, the actuator has to be capable of applying the defined torque and performing the intended safety function of the device. 

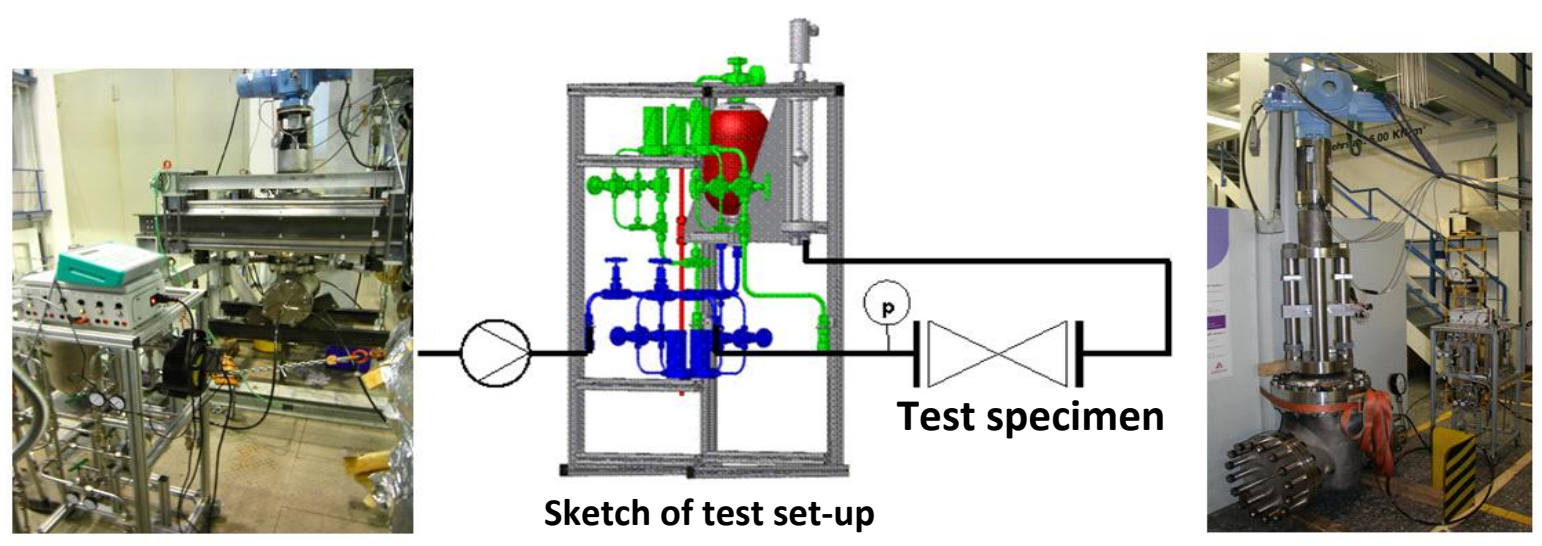

Fig. 2 Leakage measurement device (left photo: test device; middle sketch: test set-up; right photo: device connected to test valve).

\subsection{Sealing Capability}

During the different test sequences of a valve, it is a common requirement to show that the valve fulfills one of the original requirements, which is sealing. For example, after the different aging steps (as described in 2.1) or after function tests, the valve is connected to test devices to check for leakage, as shown in Fig. 2 (left photo is the test device; middle sketch is the test set-up; right photo shows the device connected to a test valve). Leak tightness testing consists of two applications: testing for tightness against water or against a gas. In the case of water-tightness, the device is first flooded via a relief valve on top of the device. This ensures that no air is remaining in the piping, which could affect the measurement. In the second step, the valve is closed and, via a pump, the pressure is increased up to the operational tightness measurement point. Mini-flow rate devices will detect any flow past the valve. In a similar way, the gas tightness is tested-gas from a bottle (typically, nitrogen) is applied on the testing side.

\subsection{End Loading_Seismic Qualification}

During the course of operation of the nuclear plant, the valve must be designed to survive various design basis earthquake events. The earthquake events can cause the valve to experience a variety of loads from the movement of the valve relative to its mounting in the piping system and the motion of the valve actuator. The seismic test involves mounting the valve on a seismic shake table in a manner that simulates the installed condition. A series of tests will be used to replicate the motion that the valve will experience at a specific location within the nuclear plant. Five tests are performed to simulate the levels of an OBE (operational basis earthquake) followed by a test to simulate an SSE (safe shutdown earthquake) event. During the earthquake events, the valve is functionally tested to ensure that operation is not affected by the earthquake-induced motion. It is possible to perform the seismic test with the valve in various positions, open or closed, or in motion from one state to another. For pressure relief valves, the valve is tested with pressure applied to ensure that the motion does not result in release of the pressure. This testing provides evidence that the valve will continue to perform the intended safety function during and following an earthquake event. Fig. 3a shows, how a valve can be fixed on a shaker table and Fig. 3b shows the arrangement of the actuators of a 6-dimensional shaker table. The multi-dimensional movement capability of the shake table allows adjusting the loads to the expected loads coming from the pipes or other support structures.

\subsection{Functional Qualification}

As the different types of valves have to ensure 


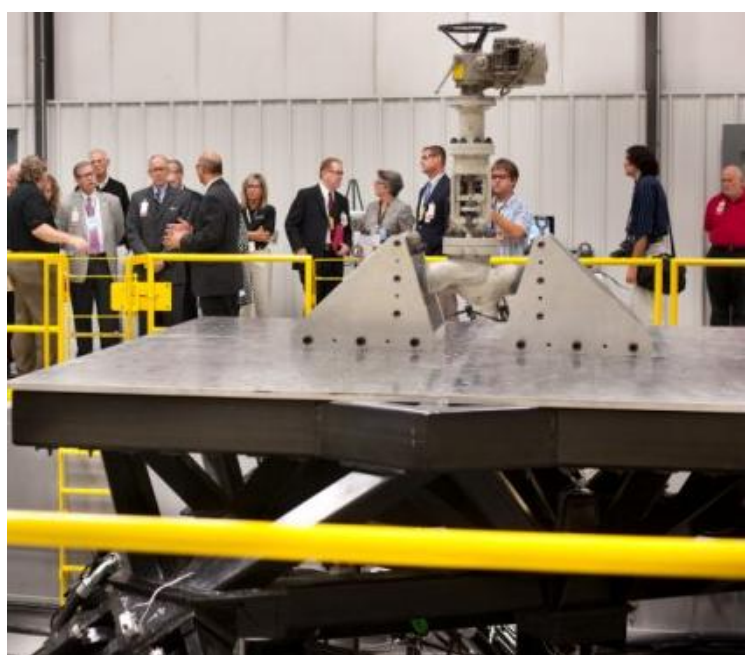

(a)

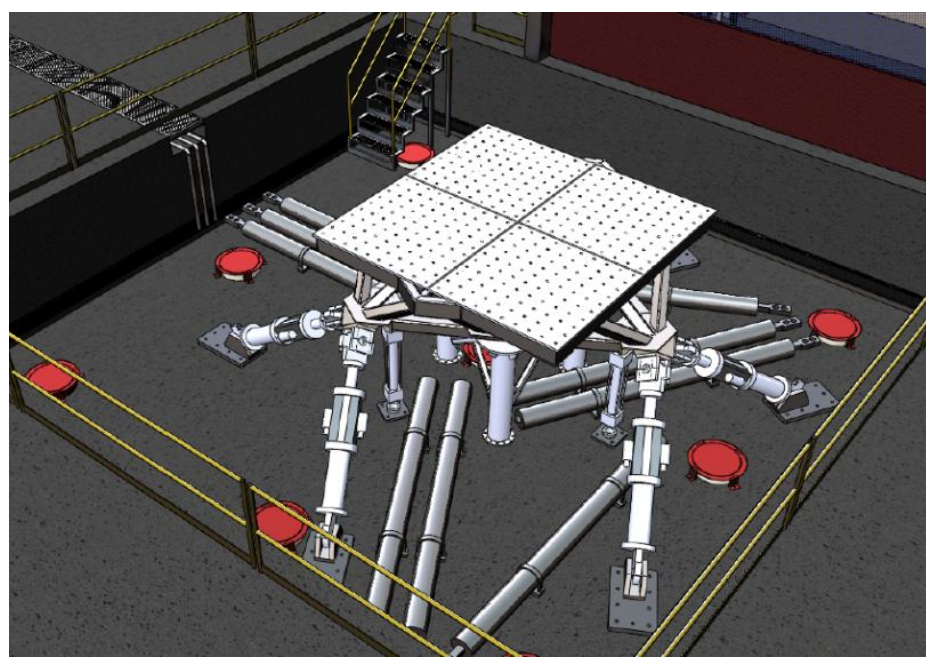

(b)

Fig. 3 (a) Shake table with a test valve; (b) Sketch actuator arrangement of the shaker table.

different functions, the types of tests to demonstrate the functioning have to be different as well. In addition, it is sometimes necessary (or reasonable) to perform different tests for one valve type to consider different aspects of the function. For example, for safety valves, one option is to test the opening and closing characteristics in one test campaign. Additional tests demonstrate the behavior under full flow conditions.

In any case, it is important to analyze the different possible operating modes of the valve and define test programs representing these operations. For this purpose, a set-up of different test facilities is necessary. Typical functioning requirements and the related test facilities are described below.

\subsubsection{Cycling}

Cycling tests determine whether a valve closes and opens under operational conditions. AREVA operates two facilities to perform this type of testing. The main design concept is the same for both, but they have different maximal flow rates. Assuming operational velocities of $5 \mathrm{~m} / \mathrm{s}$, it is possible to use the KOPRA-APS loop for valve diameters of up to 150 $\mathrm{mm}$. A sketch of this loop is shown in the left part of Fig. 7. The pressure in the loop can be adjusted with a pressurizer, and the fluid temperature is controlled via a cooler in the bypass over the pump. The loop is designed in such a way that valves of different diameters can be installed in parallel. During the tests, the valve will be opened and closed-typically up to 1,000 times. An additional bypass around the pump ensures a continuous run during the cycling tests. For valves with diameters bigger than $150 \mathrm{~mm}$, AREVA operates the KOPRA-KVA loop [6]. Fig. 4 shows a photo and the isometry of the pipe lay-out of this loop.

\subsubsection{High Energy Pipe Rupture-Outflow}

One function of valves in NPPs is to seal pipes in case of a pipe rupture. A typical valve for this application is the main steam isolation valves behind the steam generators. In the case of a pipe rupture of the main steam line, this type of valve closes to prevent a quick emptying of the steam generator. In this scenario, very high flow rates - up to the speed of sound - can occur. Fig. 5 shows a sketch and a photo of the very large valve test platform known as GAP, which is capable of simulating this kind of scenario. For this purpose, the GAP has a big vessel, which acts as an accumulator. This accumulator is filled with saturated water (via a $22 \mathrm{MW}$ boiler) at a pressure above the operational pressure of the test valve (indicated in Fig. 5 as a test specimen). Outflow is established by quickly opening the valves. When the testing flow conditions are reached, closing of the valve is initiated. The accumulator has an additional pipe at the bottom, 


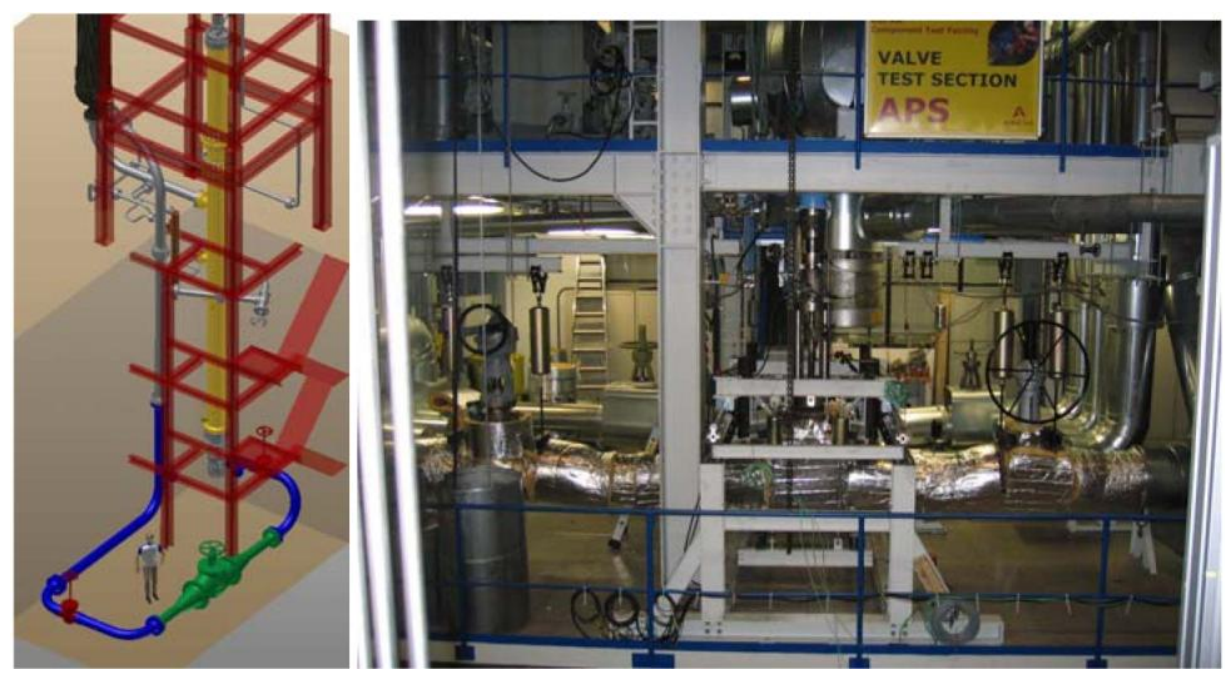

Fig. 4 Isometry and photo of the KOPRA-KVA loop.
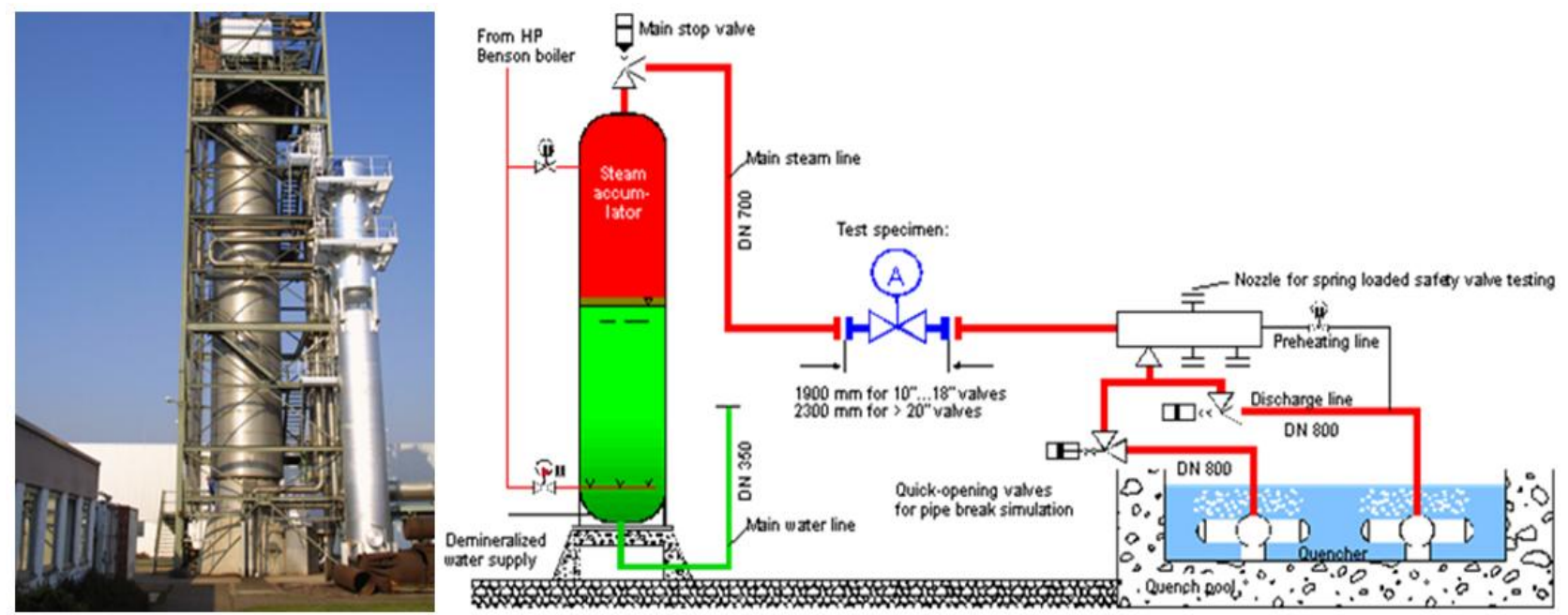

Fig. 5 Photo of the accumulator of the GAP and Sketch of the GAP.

which can be connected to the test specimen (green line in Fig. 5). In this case, water will go through the test specimen. Such an arrangement is also used to test main feed water insulation valves.

Fig. 6 shows as an example of a test run with a water steam mixture flowing through the test object. The main objective was to demonstrate that the valve closes in the appropriated time. For this purpose steady state flow conditions have been established, while the valve is open. An indicator for the proper establishment of the flow condition are the almost constant flow conditions at about $8.5 \mathrm{~s}$ with a total mass flow above $4,000 \mathrm{~kg} / \mathrm{s}$ and a pressure above $75 \mathrm{bar}$. At this time the closing command is given. The closing time of the valve can be derived from the measurement of the mass flow rates, which reaches a value of $0 \mathrm{~kg} / \mathrm{s}$ within less than 2 seconds (from closing command time about 8.5 $\mathrm{s}$ to $0 \mathrm{~kg} / \mathrm{s}$ at $10 \mathrm{~s}$ ).

\subsubsection{Set Pressures}

For safety valves, especially the pressurizer safety valves or their pilot valves, it is important to test and/or adjust the set-pressure and the closing pressure. The KOPRA-APS can be used for this purpose. By limiting the lift of the valve, lower flow rates can be achieved, with the consequence that smaller sized vessels, compared to the GAP, can be used. Another benefit is that the energy consumption is also significantly lower than that for the GAP. 


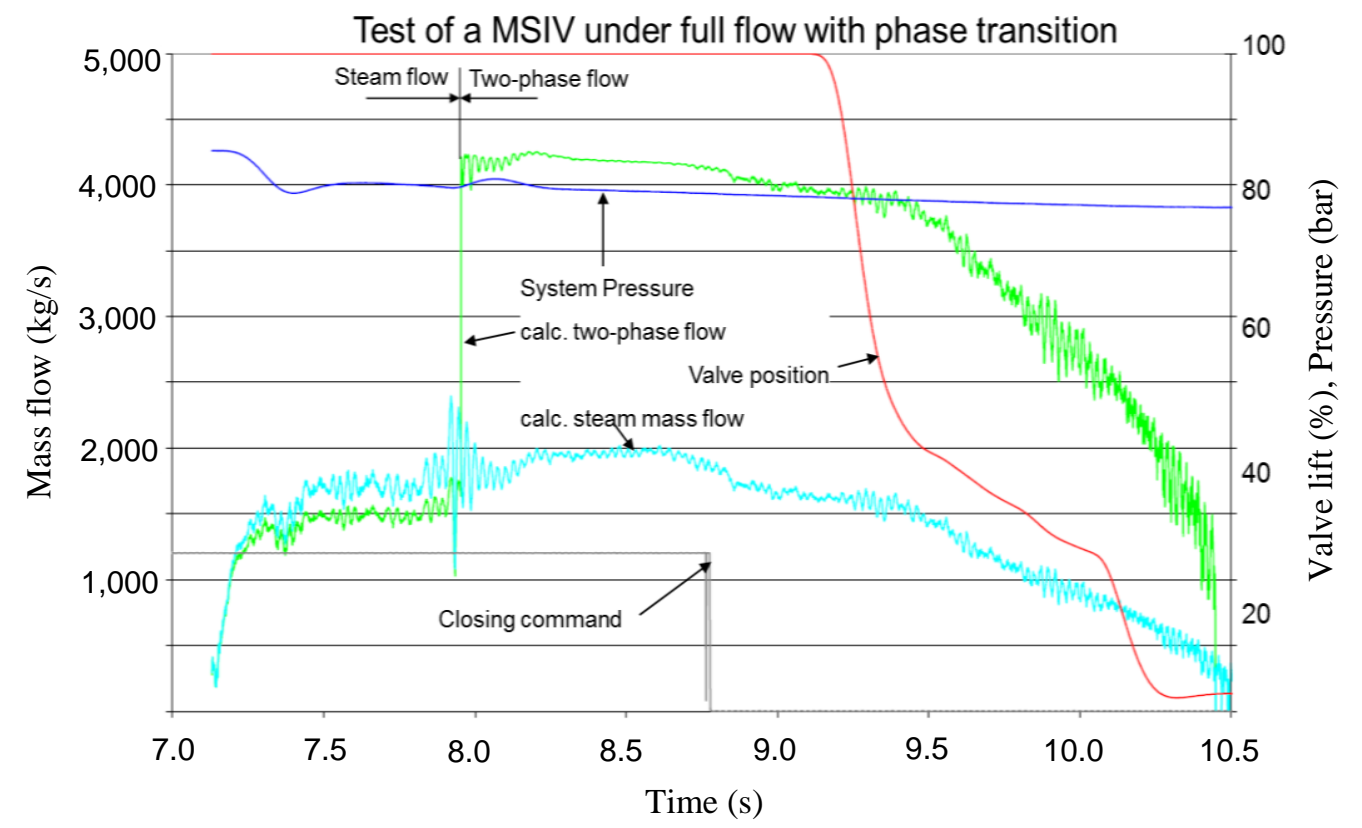

Fig. 6 Typical transient conditions during a flow interruption test.

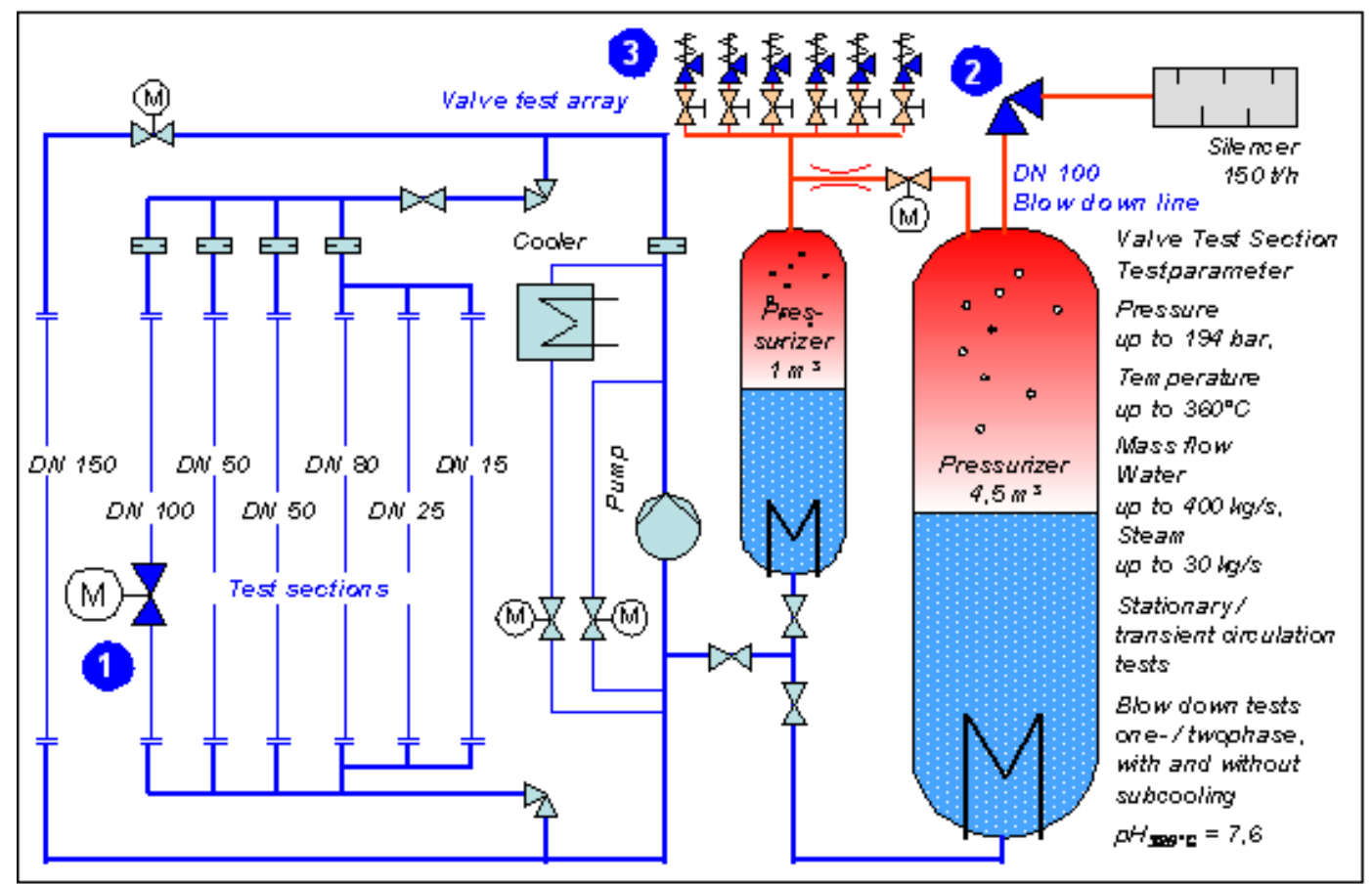

Fig. 7 Sketch of the KOPRA-APS (Cycling section is on the left and safety valve adjustment is on the right).

The safety valve test section is shown on the right in Fig. 7. It consists mainly of two pressurizers connected via a valve to the test valves, which can be pilot valves or direct safety valves. The KOPRA is designed in such a way that it can be used for newly designed/ manufactured valves as well as for valves that have been in service in an NPP. Thus, the steam going through the silencer can be sent in a condensation chamber that is closed and can accumulate a certain level of contamination. This leads to an application suitable for outage optimization. In this particular case, the one set of valves is adjusted prior to the outage in 
the test facility to replace the current set in the plant. By this measure, one gets the valves already adjusted for operating condition without affecting the outage's critical path [7].

Fig. 8 shows a typical transient flow diagram of a set pressure test. The lift has been limited to $2.2 \mathrm{~mm}$, as it is not important to demonstrate the full flow capability, which could be tested for example with the GAP or another similar loop for higher pressures. In this case pilot valves have been tested. Therefore, the pressure before the valve as well as the pressure in the control volume for opening the main valve is of relevance. Both values are shown in Fig. 8. The opening and closing time can be derived from the plot of the lift and the opening and closing pressure.

\subsubsection{Thermal Shock}

Thermal transients can occur in NPP, such as during transients, when water has been cooled down in the part of a piping system that was switched off. When this switched-off part is reconnected to the system, the water can be pulled out by hot water. This can lead to a quick change of the inner surface of the affected valve, causing deformation due to restrained thermal expansion. Testing such valves requires a loop with both cold- and hot-water loop. The valve has to be installed between the two loops. In Fig. 9 on the left is shown, how such an additional test structure has been moved between a cold and hot supply loop. As shown in the pipe layout scheme in Fig. 9 on the right this additional structure has been moved into a pit-to ensure in the case of an opening of a flange during a thermal transient, that no persons will be hurt. The flow through the test valve is feed either from the hot or cold loop. Specific safety aspects must be considered, because not only the valve itself will be shocked, but also parts of the connecting loop. Because temperatures can rise as high as $220 \mathrm{~K}$, the design of the valve and connecting loops must ensure that no cracks can occur. As shown flow in scheme in Fig. 10, consists the loop in additional a capture vessel, which collects the thermal plug going through the test specimen, to avoid, that the loop itself will reach a temperature in between the two.

\subsubsection{Particle-Loaded Fluids}

It is a common design requirement for NPP that, in the case of a LOCA, water will be sucked from the
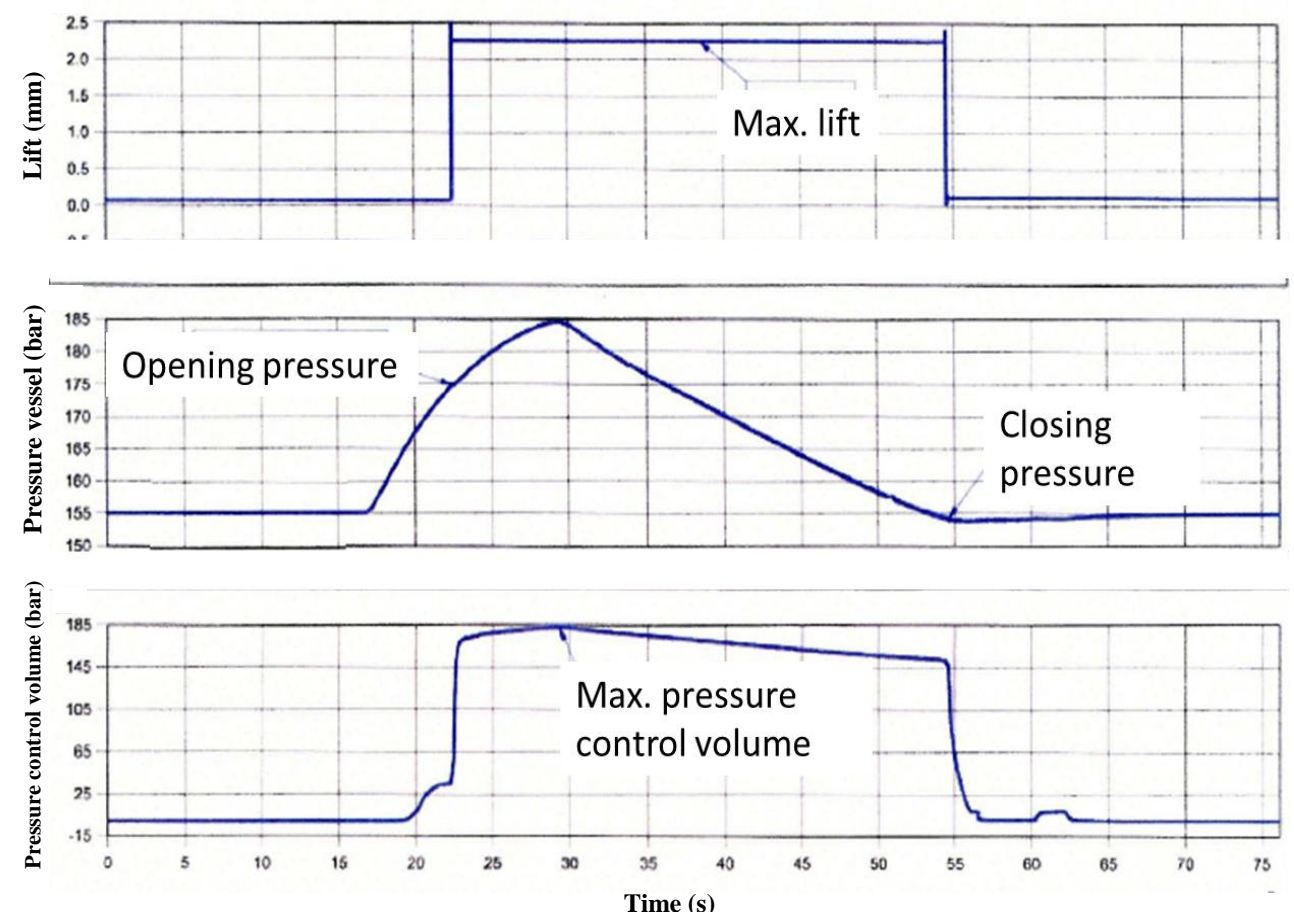

Fig. 8 Pressure transient during set-pressure tests. 

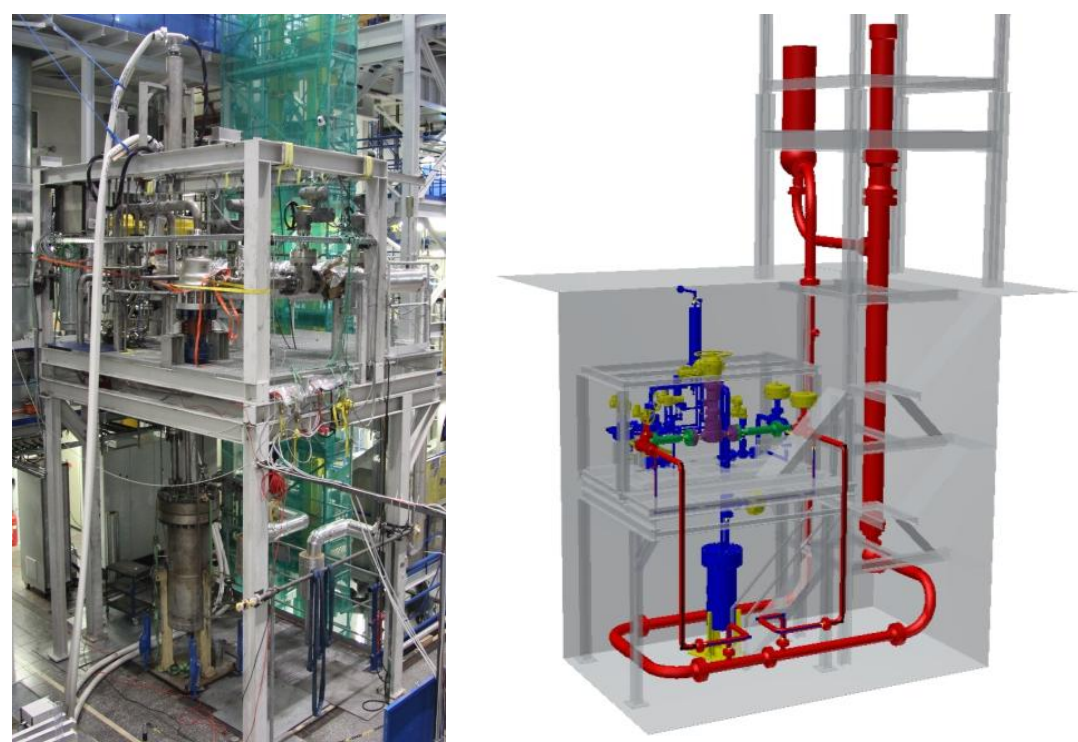

Fig. 9 Left: photo integration of a connection unit between a cold and hot loop with the test specimen; Right: piping scheme of the connection unit between the cold and hot loop.

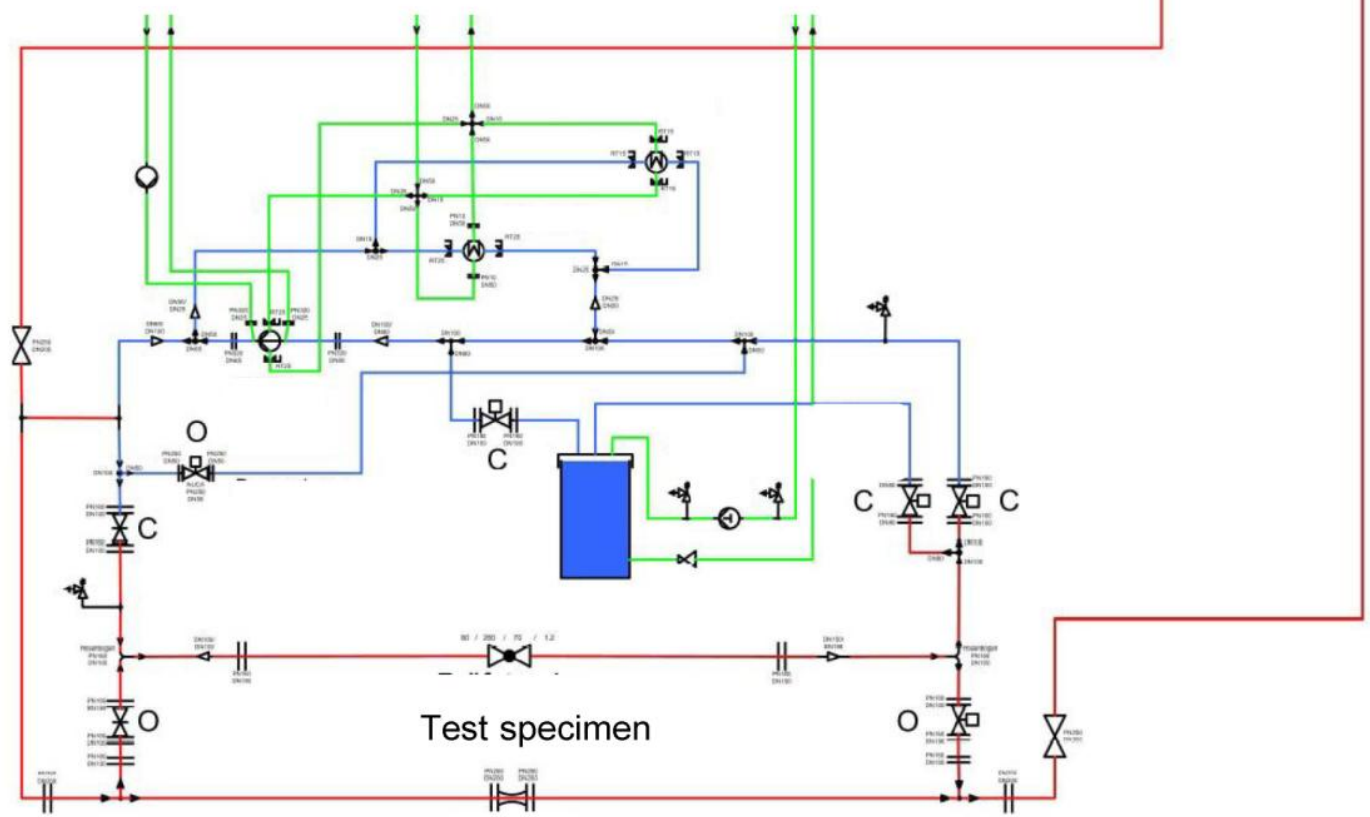

Fig. 10 Set-up of the sketch of a thermal shock loop—blue lines indicate the cold loop; red lines indicate the hot loop.

sump through sieves back into the core to ensure cooling. The entire chain of components in the related piping system must be properly qualified. This can require - in addition to the above-mentioned tests (thermal shock and cycling) - tests that consider whether the valve will properly close even if the water contains a certain amount of debris. Therefore, a loop like the one shown in Fig. 11 must be used. Such a loop contains a vessel where the debris has to be prepared. Special attention is required to ensure that the concentration remains within specification inside the loop and during its operation. If the test goal is to check that the proper closing of different valves in the loop do not influence each other, it is possible to install a series 


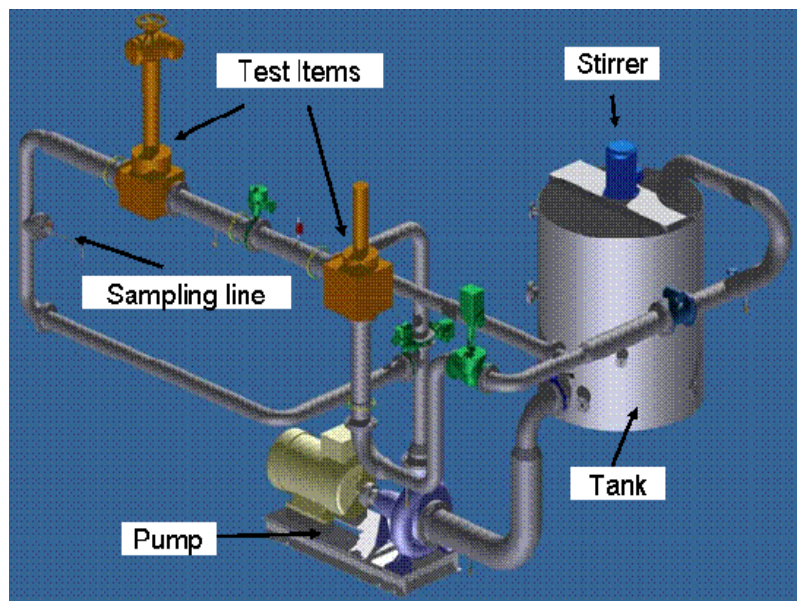

Fig. 11 Valve test section for particle-loaded water.

of valves in one test, as long as they follow the same test specification [8].

\section{Conclusions}

To qualify safety-related components, it is important to understand their operation throughout the entire life cycle of the components, including different applied loads, which may cause failures. This understanding is the basis for analyzing the reliability of the components, whether they are new components or existing components being used in a new application. In many cases, engineering analysis alone is not adequate to qualify the components. Sometimes, it is necessary to perform adequate tests in a qualification program. A qualification program requires the appropriate testing infrastructure and a qualified testing team. Accreditation of the testing team by a recognized test/inspection organization is a very good indicator of the team's ability to fulfill essential requirements in a variety of applications to ensure the performance of safety-related nuclear qualification tests.

\section{References}

[1] IEEE Standard 323, Standard for Qualifying Class 1E Equipment for Nuclear Generating Stations.

[2] IEEE Standard 344, Recommended Practices for Seismic Qualification of Class 1E Equipment for Nuclear Generating Stations.

[3] ASME NQA-1, Quality Assurance Requirements for Nuclear Facility Applications.

[4] Ganzmann, I., Herr, W., Schmidt, H., Stecher, W., Walter, D., Umminger, K., Beisiegel, A., Wich, M., Dolleans, P., and Muller, T. 2011. AREVA's Thermo-Hydraulic Platform Qualified as Test and Inspection Body VGB Power Tech.

[5] Schonert, T., Klotz, H. J., Beisiegel, A., and Wich, M. 2011. "Enviromental Qualifgications of Electrical Instrumentation and Control (I\&C) Components." Presented at Annular Meeting on Nuclear Technology, Berlin, Germany.

[6] Sykora, A., Herr, W., and Champomier, F. 2008. "Full Scale Component Test Facility KOPRA-Qualification Test of EPR Control Rod Drive Mechanism.” Presented at International Youth Nuclear Congress, Interlaken, Switzerland.

[7] Först, A., Beisiegel, A., Wallaschek, S., Stecher, W., Schmidt, H., and Fortes, R. L. 2014. "Pressurizer Safety Valve Adjustment under the Focus of Optimizd Outage Duration and Plant Availability." Presented at the 40th Reunión Anual de la Sociedad Nuclear Española, Valencia.

[8] Ganzmann, I., and Schmidt, H. 2014. "Qualification of Pumps and Valves for the Safety Injection Path of Nuclear Power Plants." In Proceedings of the ASME/NRC 12th Symposium on Valves, Pumps, and Inservice Testing for Operating and New Reactors. 